Aletria, Belo Horizonte, v. 29, n. 4, p. 165-189, 2019

(c) (i)

\title{
Entre el exceso y la escasez. Testimonio y memoria en documentales sobre la militancia revolucionaria en Argentina y Brasil ${ }^{1}$
}

\section{Between Excess and Shortage. Testimony and Memory in Documentaries about Revolutionary Militancy in Argentina and Brazil}

\author{
Graciela Foglia \\ Universidade Federal de São Paulo (Unifesp), São Paulo, São Paulo / Brasil \\ graciela.foglia@unifesp.br
}

Resumen: Hasta comienzos de los años 2000, en Argentina y Brasil, frente a la desproporción de la violencia estatal que exterminó a miles de militantes y no militantes, varios de los documentales que abordan esa temática se centraron en la memoria, entre reivindicativa y traumática, de la militancia y de la dictadura. Sin embargo, aunque en menor medida, en esas películas además de la reflexión y autocrítica sobre las acciones que condujeron al fracaso de la lucha revolucionaria, hay espacio para lo que el historiador italiano Alessandro Portelli llama "memoria perturbadora". En este artículo se examinan e interpretan, en el marco de las reflexiones sobre testimonio, semejanzas y diferencias en el abordaje de las memorias traumáticas y perturbadoras en los documentales Errepé de Gabriel Corvi y Gustavo de Jesús (Argentina, 2003) y Tempo de resistência de André Ristum (Brasil, 2004).

Palabras clave: Errepé; Tempo de resistência; memorias traumáticas; memorias perturbadoras; dictaduras latinoamericanas.

\footnotetext{
${ }^{1}$ Una versión resumida de este trabajo fue leída en el VII Coloquio Internacional de Estudios Latinoamericanos de Olomouc, República Checa (Cielo-7), en mayo de 2018. El artículo forma parte de un proyecto de posdoctorado que fue desarrollado en la Faculdade de Filosofia, Letras e Ciências Humas de la Universidade de São Paulo (FFLCH-USP) y fue parcialmente financiado por la São Paulo Research Foundation (Fapesp): Grant\#2015/12748-5.
} 


\begin{abstract}
Until the early 2000s, in Argentina and Brazil, in the face of the disproportion of state violence that killed thousands of militants and non-militants, several of the documentaries that address this issue focused on the memory, between vindictive and traumatic, of militancy and dictatorship. However, although to a lesser extent, in those films in addition to reflection and self-criticism about the actions that led to the failure of the revolutionary struggle, there is room for what the Italian historian Alessandro Portelli calls "disturbing memory." This article examines and interprets, within the framework of reflections on testimony, similarities, and differences in the approach to traumatic and disturbing memories in the documentaries Errepé, by Gabriel Corvi and Gustavo de Jesús (Argentina, 2003), and Tempo de resistência, by André Ristum (Brazil, 2004).
\end{abstract}

Keywords: Errepé; Tempo de resistência; traumatic memories; disturbing memories; Latin American dictatorships.

Cuando se habla de testimonio y memoria en el ámbito de la literatura o del cine, se suele aceptar la necesidad de ambos como una manera de hacer conocer y concientizar sobre diferentes crímenes perpetrados por los Estados -genocidio, lesa humanidad, guerra $-^{2} \mathrm{y}$ así ayudar a crear condiciones para que no se repita la barbarie. En ese sentido, en Argentina y Brasil, frente a la desproporción de la violencia estatal que exterminó a cientos y miles de militantes y no militantes, parece razonable que hasta comienzos de los años 2000, a casi veinte del final de las dictaduras, y después de una larga década de políticas que intentaron borrar el recuerdo del pasado dictatorial, varios de los documentales que resistían a dicha operación se centrasen en la memoria, entre reivindicativa y traumática, de la militancia y de la dictadura.

Sin embargo, aunque en menor medida, en dichas producciones cinematográficas además de la reflexión y autocrítica sobre las acciones que condujeron al fracaso de la lucha revolucionaria, también hay espacio para lo que el historiador italiano Alessandro Portelli llama "memoria perturbadora", ${ }^{3}$ memoria como molestia, negada y reprimida, contrapuesta a la memoria-monumento, la oficial, autorizada y, de alguna

\footnotetext{
${ }^{2}$ Para una definición de esos crímenes ver el Estatuto de Roma, de la Corte Penal Internacional.

${ }^{3}$ PORTELLI. Sobre los usos de la memoria: memoria-monumento, memoria involuntaria, memoria perturbadora
} 
manera, tranquilizadora. Para el autor, esta última, construida en relación a la resistencia durante la Segunda Guerra Mundial, "se materializa en monumentos a los partisanos mártires [...], nunca a los partisanos que, en la guerra justa contra el fascismo y el nazismo, dispara[n] e inevitablemente mata[n]". ${ }^{4}$ Lo que trae consecuencias tanto en el plano público como en el individual. En lo que se refiere a lo público, olvidar el horror de las foibes, en las que fueron enterrados millares de italianos ejecutados por los partisanos del Partido Comunista de Yugoslavia, hace que actualmente se enarbole ese hecho como contrargumento frente a las atrocidades nazis y fascistas "construyendo versiones exageradas e instrumentales que se utilizan para deslegitimar no solo la memoria de la Resistencia sino toda la construcción democrática que derivó de ella". ${ }^{5}$ En el plano individual, no considerar las memorias perturbadoras "produce dolorosas disociaciones dentro de las conciencias [...] Es una disociación que empieza en el momento mismo de la acción, y sigue en la memoria". ${ }^{6}$ Portelli cita el caso de una mujer muy religiosa que durante la ocupación nazi llevó a cabo varias operaciones de guerrilla armada: "Durante la Resistencia yo pensaba: es como si estuviera transgrediendo,

\footnotetext{
${ }^{4}$ PORTELLI. Sobre los usos de la memoria: memoria-monumento, memoria involuntaria, memoria perturbadora, p. 115.

${ }^{5}$ PORTELLI. Sobre los usos de la memoria: memoria-monumento, memoria involuntaria, memoria perturbadora, p. 116. En lo que se refiere a las operaciones deslegitimadoras de la memoria construida por las organizaciones de Derechos Humanos, tanto en Argentina como en Brasil se alzan voces que reclaman "memoria completa"; sintagma que oculta que la militancia revolucionaria fue combatida fuera de la ley -con tortura, muerte y desaparición-, ya sea que se consideren los tratados internacionales sobre la guerra, ya sea que se tengan en cuenta las leyes del Estado. En Argentina, con ese eslogan, "Memoria Completa", surgido a comienzos de los años 2000, "el ejército buscó [...] posicionarse públicamente con un discurso verosímil capaz de disputarles a los organismos de derechos humanos la verdad sobre el pasado reciente" (SALVI. De vencidos a víctimas: memorias militares sobre el pasado reciente en la Argentina, p. 55). En Brasil, desde el liberalismo y la derecha, dueños de los grandes medios de comunicación, aunaron voces en 2015 para deslegitimar el documento final de la Comisión Nacional de la Verdad (CNV), que investigó los crímenes de la dictadura brasileña casi 30 años después de acabada (NAPOLITANO. Recordar é vencer: as dinâmicas e vicissitudes da construção da memória sobre o regime militar brasileiro, p. 36).

${ }^{6}$ PORTELLI. Sobre los usos de la memoria: memoria-monumento, memoria involuntaria, memoria perturbadora, p. 116.
} 
me daba vergüenza dirigirme a Él [a Cristo]. Si lo pienso después digo: qué extraño, ¿era realmente yo la que hacía esto?"7

Los documentales que abordan el tema de la militancia revolucionaria en Argentina y Brasil de alguna manera evitan (o intentan evitar $)^{8}$ las consecuencias que señala Portelli ${ }^{9}$ cuando no hay espacio para lo inquietante. Como veremos, le dan cabida también a ese tipo de memoria y así, por un lado, pueden enfrentar las operaciones deslegitimadoras y, por otro, al incluir el recuerdo personal de los combatientes revolucionarios - cuya ética en general es distinta de la de los que comandaron y colaboraron con la represión- que participaron en la guerrilla y llevaron a cabo "acciones que contrastan con su propia consciencia y con la ética del tiempo de paz"10 disminuyen los riesgos de las "dolorosas disociaciones" como las del ejemplo antes referido.

Teniendo en cuenta las observaciones anteriores, aquí me propongo examinar e interpretar, en el marco de las reflexiones sobre testimonio, semejanzas y diferencias en el abordaje de las memorias traumáticas y perturbadoras (que, como veremos, también pueden ser traumáticas) en los documentales Errepé de Gabriel Corvi y Gustavo de Jesús (Argentina, 2003) y Tempo de resistência dirigido por André Ristum (Brasil, 2004). Se trata de dos películas que, mediante los recuerdos de militantes de organizaciones armadas de los años 1960 y 1970, recorren la historia de aquel tiempo en Argentina y en Brasil y la historia de las propias organizaciones. ${ }^{11}$

Veremos en esas películas que los contenidos y formas de los relatos testimoniales están atravesados por la característica que

\footnotetext{
7 PORTELLI. Sobre los usos de la memoria: memoria-monumento, memoria involuntaria, memoria perturbadora, p. 116-117.

${ }^{8}$ Para Argentina, esto ya es patente desde los años 1990 en películas como Cazadores de utopías (Blaustein, 1996) o Montoneros, una historia (Di Tella, 1998). Para Brasil, en los 2000, se pueden mencionar, además del documental que será trabajado en este artículo, Vlado, 30 anos depois (João Batista de Andrade, 2005), Hércules 56 (Da-Rin, 2007).

9 PORTELLI. Sobre los usos de la memoria: memoria-monumento, memoria involuntaria, memoria perturbadora.

${ }^{10}$ PORTELLI. Sobre los usos de la memoria: memoria-monumento, memoria involuntaria, memoria perturbadora, p. 116.

${ }^{11}$ Como señalé en otro artículo, intentar clasificar la producción documental de ambos países de forma similar no es una transposición directa (ver FOGLIA. Confrontar lo indecible en el cine documental argentino y brasileño: los casos Urondo y Herzog).
} 
marca al testimonio y que puede sintetizarse como la imposibilidad de "comprender armoniosamente el horror", ${ }^{12}$ o, dicho de otra manera, los relatos están marcados por la imposibilidad, para el sujeto de enunciación del testimonio, de superar el abismo entre el impacto de la catástrofe y los medios de hacerlo palabras, de modo que la expresión puede volverse imprecisa o insuficiente. ${ }^{13}$ La cita anterior de Nestrovski y SeligmannSilva se refiere a las obras de arte que abordan la Shoah, sin embargo parece pertinente traerla aquí pues la experiencia de matar, para la ética revolucionaria, o la privación ilegítima de la libertad, la tortura y el asesinato, aun en dimensiones diferentes de las del exterminio en los campos de concentración nazi, son acciones humanas que ponen a prueba el entendimiento. Pero, además, como continúan reflexionando los autores, Auschwitz "desafía, para siempre, las formas de pensar, elaborar, representar -y no solo en lo que se refiere al holocausto". ${ }^{14}$

En lo que se refiere a las diferencias se verá que, en el caso brasileño, el documental abre más espacio para las memorias traumáticas y en el argentino, para las perturbadoras. Para interpretar esa disimilitud, vale la pena considerar las distintas representaciones de la dictadura y de la lucha revolucionaria en cada país. En Brasil, en general, se borra el recuerdo de esta última. Napolitano se refiere a una memoria social hegemónica, crítica a la dictadura, que celebra la resistencia, pero desconsidera otros ideales de izquierda. ${ }^{15}$ En el proceso de construcción de esa memoria hegemónica, que el autor llama "liberal-conservadora", ${ }^{16}$ se adoptan valores y discursos de la izquierda no armada, como los del Partido Comunista Brasilero, que ponen el foco en la categoría "resistencia", capaz de reunir las identidades políticas de ese momento. ${ }^{17}$ En Argentina, en cambio, si al comienzo

12 "[...] compreender harmoniosamente o horror". (NESTROVSKI; SELIGMANNSILVA. Apresentação, p. 10, traducción mía).

${ }^{13}$ GUINZBURG. Crítica em tempos de violência, p. 55.

14 “"...] desafía para sempre as formas de pensar, elaborar, representar - e não só no que tange ao holocausto" (NESTROVSKI; SELIGMANN-SILVA. Apresentação, p. 10 , traducción y cursivas mías).

${ }^{15}$ NAPOLITANO. Recordar é vencer: as dinâmicas e vicissitudes da construção da memória sobre o regime militar brasileiro.

${ }^{16}$ NAPOLITANO. Recordar é vencer: as dinâmicas e vicissitudes da construção da memória sobre o regime militar brasileiro, p. 19.

${ }^{17}$ NAPOLITANO. Recordar é vencer: as dinâmicas e vicissitudes da construção da memória sobre o regime militar brasileiro, p. 17-18. 
de la democracia se intentó instalar la idea de que los militares habían cometido "excesos y errores" y borrar la relación directa entre la represión y las actividades políticas de desaparecidos, asesinados, miles de presos políticos, cesanteados y exiliados, con el tiempo se fue haciendo una tarea de concientización social en la cual las víctimas recuperaron sus trayectorias militantes y la dictadura su ferocidad "por haber desarrollado una sistemática y planificada represión". ${ }^{18}$

\section{Tensiones entre memoria e historia}

Antes de focalizar los testimonios individuales, abordo brevemente la forma general de los documentales, igualmente marcada por la dificultad de poder comprender armoniosamente la violencia ejercida por seres humanos sobre mujeres y hombres.

Para presentar el pasado de la militancia revolucionaria ambas películas se estructuran cronológicamente con varias declaraciones asertivas y explicativas y abundante material de archivo. Debido a esa marcada estructuración, a primera vista se podría preguntar en qué medida Errepé y Tempo de resistência son documentales de memoria. Siguiendo a Aprea, se sabe que en ese tipo de película, junto con el material institucional, se usan diferentes recursos para explicitar el punto de vista subjetivo. ${ }^{19}$ Por un lado, el propio testimonio de los/las involucrados/as que no se restringe a la información: incluye impresiones personales, afectividad, juicios y opiniones de quienes vivieron y padecieron los efectos de la situación histórica recordada. Por otro, se suelen usar registros que se vinculan a la vida personal de los/las entrevistados/as: fotos o filmaciones familiares u objetos que destacan la subjetividad de la mirada, la elección de una determinada perspectiva sobre los hechos. Si además se considera que la historia "tiene como objetivo la exactitud de la representación" y que se preocupa por poner orden, mientras que la memoria "está atravesada por el desorden de la pasión, de las emociones y de los afectos", ${ }^{20}$ se puede decir que en ambas películas la confrontación con la experiencia de los años 1960 y 1970 pone en tensión memoria e historia. Tensión que puede ser pensada

\footnotetext{
${ }^{18}$ MANGONE. "Por algo será", p. 9.

${ }^{19}$ APREA. Documental, testimonios y memorias: miradas sobre el pasado militante, p. 122.

${ }^{20}$ CANDAU. Antropología de la memoria, p. 56-57.
} 
como provocada por la dificultad de una representación tranquilizadora y única de un enfrentamiento en el cual, por un lado, se destruyeron muchas vidas que buscaban un mundo mejor y, por otro, coloca un problema ético frente a la experiencia de la violencia.

Sin embargo, si el orden cronológico, las "voces de autoridad", los fragmentos de películas, que ya son parte del registro de la Historia, ${ }^{21}$ y el material institucional de $\operatorname{archivo~}^{22}$ parece que desdibujan las marcas de memoria, otros recursos la ponen en escena. Veamos.

En la tipología de Nichols, Tempo de resistência sería un documental del tipo "expositivo"-aquellos en los que predomina una voz de autoridad, que "se dirige al espectador directamente, con intertítulos o voces que exponen una argumentación acerca del mundo histórico"-, ${ }^{23}$ modo ideal para transmitir información, en el que tanto las imágenes como las entrevistas, en general, sirven para ilustrar y demostrar el argumento de la película. ${ }^{24}$ Ahora bien, aunque el filme sigue rígidamente esa forma-aproximadamente 37 secuencias, introducidas por la misma cantidad de intertítulos informativos y explicativos (en promedio casi uno cada tres minutos)- la rigidez es atenuada con fotos personales de los/las entrevistados/as aun cuando no se relacionen directamente con lo que se está tratando -ver, por ejemplo, la fotografía de Leopoldo Paulino, con 13 años, del brazo, tal vez, de su madre ${ }^{25}$ y con varios testimonios

${ }^{21}$ En Errepé, los fragmentos son de películas de "Cine de Base", brazo cultural del PRT. En Tempo de resistência son de filmes de Silvio Tendler, cineasta e historiador que produjo los documentales Anos JK, uma trajetória política (1980) y Jango (1984), sobre los expresidentes Juscelino Kubitschek (1956-1961) y João Goulart (1961-1964). ${ }^{22}$ Para Lanza el uso de estos materiales en América Latina sigue una línea casi hegemónica: se los considera documentos comprobatorios, "portadores de verdad y registro inalterable" (LANZA. Usos del archivo en el cine documental latinoamericano contemporáneo: los documentos sobrevivientes).

${ }^{23}$ NICHOLS. La representación de la realidad: cuestiones y conceptos sobre el documental, p. 68.

${ }^{24}$ En la película de Ristum, el argumento es el que anuncia el título: pensar los años de la lucha revolucionaria como años de resistencia. En Errepé, se trata de un cuestionamiento a la autocrítica, que está enunciado en el epígrafe “¿En nombre de qué presente tenemos el derecho de criticar nuestro pasado?", y queda a criterio del espectador responder. Hago esta afirmación teniendo en cuenta las imágenes del presente (2003) que aparecen casi al final de la película (ERREPÉ. 1:48:17 h), antes del epílogo, que muestran la pobreza de las comunidades que viven en villas miseria.

${ }^{25}$ ERREPÉ, 00:05:03 h. 
marcados por afectos y emociones. A modo de ejemplo, se puede pensar en las descripciones y declaraciones afectivas del exmilitante de la Ação Libertadora Nacional (ALN) Aloysio Nunes Ferreira ${ }^{26}$ sobre Carlos Marighella, fundador del grupo guerrillero: "era un personaje fascinante [...] Era un hombre grande, bonito [...] un sujeto muy cálido, era cariñoso, bromeaba, tenía buen humor [...] fue una convivencia que me deja mucha nostalgia", ${ }^{27}$ o ver el llanto desconsolado de Denise Crispim, ${ }^{28}$ también exmilitante de ALN, compañera de Eduardo Collen Leite, Bacuri, contando el último encuentro de los dos, ${ }^{29}$ en prisión, frente al comisario Fleury, uno de los represores más violentos de la dictadura brasileña.

Por su parte, Errepé tiene más características del documental del modo participativo, aquel en el que el cineasta interactúa con los entrevistados/as; sin embargo, las emociones y afectos están más contenidos: no hay, por ejemplo, comentarios que muestren admiraciones individuales sobre Roberto Santucho, uno de los fundadores del PRT, y las únicas fotos personales aparecen recién después de más de una hora y media de película y en general son de los militantes muertos o desaparecidos, cuya voz ya no puede oírse. Pero, a pesar de ese aparente distanciamiento de lo más personal, la interpelación "sorpresa" de los realizadores permite respuestas más espontáneas, que pueden requerir búsquedas de argumentos, pero también búsquedas en la memoria. Como ejemplo, se puede considerar la secuencia sobre el secuestro de Oberdan Sallustro, ${ }^{30}$ que comento más adelante.

Además, en Errepé, por estar más librado a lo espontáneo y por las pocas indicaciones temporales y espaciales, se crea la ilusión de seguir una especie de "flujo de memoria", provocando la sensación de

\footnotetext{
${ }^{26}$ Nunes Ferreira fue militante del PCB y de Ação Libertadora Nacional (ALN) de donde se alejó cuando estaba exiliado en París. A partir de ahí estuvo afiliado a diferentes partidos de centro derecha hasta que en 2016 fue uno de los senadores que votó a favor de la destitución de la presidenta Dilma Rousseff.

27 " [...] era um personagem fascinante [...] Era um homem grande, bonito [...] um sujeito muito caloroso, ele era carinhoso, brincava, ele tinha bom humor [...] foi uma convivência que me deixa muita saudade" (TEMPO DE RESISTENNCIA, 1:06:28 h, traducción mía).

${ }^{28}$ TEMPO DE RESISTÊNCIA, 1:34:40 h.

${ }^{29}$ La historia de ambos y el posterior exilio de Crispim y su hija están en el documental Repare bem (Medeiros, 2013).

${ }^{30}$ ERREPÉ, 00:29:16 h.
} 
desorden de la que habla Candau, ${ }^{31}$ sobre todo para quien no conoce la historia de la guerrilla en Argentina. En este sentido, los tres primeros minutos de cada película son un ejemplo que las diferencias. En el documental argentino la dedicatoria "a Jorge", el letrero con la fecha 25/05/1973, la manifestación y la consigna: "Todos los guerrilleros son nuestros compañeros", ${ }^{32}$ el fragmento de discurso desde las ventanas de una cárcel; la voz en off recordando aquel momento y las consignas ("5X1 no va a quedar ninguno", "Santucho-Urteaga la patria liberada", "Ya van a ver, ya van a ver, cuando venguemos los muertos de Trelew", contrastan fuertemente con los tres primeros minutos iniciales de la película brasileña: antes de escuchar la voz del primer entrevistado, tres intertítulos, explicativos y didácticos, también un discurso, pero de João Goulart, presidente que sería depuesto en 1964, cuando empezó la dictadura en Brasil y también la voz off de un militante acordándose del día del golpe militar.

Abundantes informaciones y explicaciones, orden e intimismo, en la película brasileña; pocas explicaciones, sensación de desorden y distanciamiento, en la argentina. La tensión entre historia y memoria y las formas diferentes en que se ponen de manifiesto en cada documental pueden ser pensadas como distintos niveles de confianza sobre el conocimiento de la historia reciente por parte del espectador; más en Argentina, menos en Brasil. Pero también, o justamente por eso, en este último caso, lo intimista serviría como recurso para sensibilizar a un público que, por un lado, está expuesto al espectáculo diario de la violencia y a su naturalización y, por otro, poco conoce de la brutalidad dictatorial. Dice Teles que en Brasil se ha abierto un abismo con relación al conocimiento que se tiene de la historia, lo que hace que se repitan hasta hoy las estructuras autoritarias y sostiene que cuanto más se alejen en el tiempo los hechos de la dictadura, menos posibilidades habrá de transformarlos en experiencia. ${ }^{34}$ Tal vez, por eso sea necesario aceptar el exceso como herramienta de sensibilización. ${ }^{35}$

\footnotetext{
${ }^{31}$ CANDAU. Antropología de la memoria.

${ }^{32}$ ERREPÉ, 00:00:30 h.

${ }^{33}$ ERREPÉ, 00:00:54 h.

${ }^{34}$ TELES. O abismo na história: ensaios sobre o Brasil em tempos de Comissão da Verdade, p. 56.

${ }^{35}$ NESTROVSKI; SELIGMANN-SILVA. Apresentação, p. 11.
} 


\section{Exceso y escasez: memoria traumática / memoria perturbadora}

Respecto a los testimonios, abordo dos aspectos nada tranquilizadores de los documentales: por un lado, el relato de la tortura; por otro, el de la violencia revolucionaria. El primero, la tortura física, solo aparece en Tempo de resistência; en el documental argentino se recuerda la caída de compañeros/as, pero no se menciona ningún suplicio, aun habiendo entre los/las entrevistados/as quienes los sufrieron. ${ }^{36} \mathrm{En}$ cuanto a la componente de violencia ejercida por las guerrillas, aunque ninguno de los dos documentales evita relatarla, en Tempo de resistência es bastante más acotado el espacio que se le dedica, a pesar de que las organizaciones de izquierda, además de los conocidos secuestros de embajadores, también pusieron bombas, mataron policías y militares y llevaron a cabo acciones de guerrilla rural y urbana. ${ }^{37}$

\section{Tempo de resistência: estética del exceso}

Ya vimos en el apartado anterior que en Tempo de resistência hay un exceso de información cuando se lo compara con el documental argentino y cómo esa característica puede ser interpretada. En los testimonios, la profusión de relatos puede ser leída de otra forma, como discutiremos a continuación.

Desde los escritos pioneros de autores como Primo Levi ${ }^{38} \mathrm{y}$ Robert Antelme ${ }^{39}$ sobre la experiencia de los campos de concentración, se reflexiona acerca de la dificultad de representar dicha experiencia. Las palabras dejaron de decir todo y abandonaron su anhelo de describir o explicar todo, reconocen su desnudez y, a la vez, se encargan de transmitir

\footnotetext{
${ }^{36}$ A modo de ejemplo, a Graciela Draguicevich, una de las militantes que participa en el documental, le arrancaron las uñas de los pies (ver AGENCIA PARA LA LIBERTAD. Argentina. Testimonio de la sobreviviente Graciela Draguicevich ante la impunidad de sus torturadores genocidas) y a la compañera de Héctor López, éste también militante) que aparece en la película, la torturaron enfrente de su hijo de 5 años (ver MALDONADO. La Vida aún está entera dentro mío).

${ }^{37}$ GORENDER. Combate nas trevas, p. 271.

${ }^{38}$ LEVI. Si esto es un hombre.

${ }^{39}$ ANTELME. La especie humana.
} 
la experiencia de la aniquilación. ${ }^{40}$ No parecería ser este el caso -el abandono de la pretensión totalizante- de Tempo de resistência que incluye desde la narración entre asombrada e incrédula de quien fue torturado en la camilla de un hospital a la descripción detallada del cuerpo destrozado de Eduardo Leite, Bacuri; o desde los pormenores de un secuestro hasta los de la "silla de dragón"; ${ }^{41} \mathrm{o}$ la voz de quien habla por el/la que ya no puede hacerlo (Zerbini, Crispin) o no quiere (Patrocínio) hasta la reproducción o cita del habla de represores. Es como si con la sintaxis descriptiva se intentase alcanzar una totalidad, que es cuestionada por los casi siempre primerísimos planos, con los y las entrevistadas fuera de cuadro y cortadas, que evocan fragmentos de cuerpos mutilados.

Por el contrario, el metraje ficcional que acompaña esa narrativa parece, sí, ser un recurso que pone de manifiesto la insuficiencia de la palabra para referir la violencia brutal infligida por un ser humano sobre otro. La inclusión de ese metraje alude, ante lo inimaginable para los valores humanistas, a la imposibilidad de mantenerse en el campo de lo informativo. Decía Antelme en el prólogo a La especie humana, que los sobrevivientes que volvían de los campos de concentración, al intentar contar su experiencia pronto descubrieron la enorme distancia, la desproporción, entre lenguaje y experiencia vivida: "nos las teníamos que ver con una de esas realidades de las que decimos que supera la imaginación. A partir de ahí estaba claro que sólo mediante [...] la imaginación podíamos intentar decir algo al respecto." ${ }^{42}$

Pero además de intentar transmitir la experiencia de la violencia, las imágenes, que sugieren más de lo que muestran -siempre de noche, siempre borrosas y fuera de foco, que parecen reconstruir el camino a la "sucursal del infierno"- ${ }^{43}$ crean un extrañamiento que, de alguna manera, ayuda a evitar el rechazo o la naturalización que puede producir la exposición a escenas explícitas de tortura, bastante común desde películas como Pra frente Brasil (Farias, 1982) o más recientes como Batismo de sangue

\footnotetext{
${ }^{40}$ GAGNEBIN. Palavras para Hurbinek, p. 110. Si bien la reflexión de Gagnebin se refiere al testimonio literario, considero las declaraciones personales de los y las militantes a la luz de esta cita porque en los documentales forman parte del conjunto de la representación.

${ }^{41}$ Tipo de silla eléctrica casera.

${ }^{42}$ ANTELME. La especie humana, p. 6.

${ }^{43}$ TEMPO DE RESISTÊNCIA, 1:34:40 h.
} 
(Ratton, 2007). En ese mismo sentido se puede interpretar la alternancia entre la descripción de suplicios y las reflexiones sobre la "construcción de un torturador" o sobre las consecuencias de los tormentos en el sujeto torturado y en el torturador, y así no se corre el riesgo de hundirse en la compasión abstracta, en la autopreservación o en la indiferencia. ${ }^{44}$

Volviendo al testimonio, se suele hablar del tono moderado que los testigos usan para contar sus padecimientos. En un apéndice de 1976 a Si esto es un hombre, dice Primo Levi que "para escribir este libro he usado el lenguaje mesurado y sobrio del testigo" $" 45$ y Beatriz Sarlo, al comparar el teatro macabro, grand-guignol, que montó la prensa argentina cuando fueron descubiertas las primeras tumbas NN con el programa Nunca Más, juicio a las juntas militares transmitido por televisión, concluye que para presentar el ensañamiento y la locura homicida "se había elegido el medio tono. Los hechos que hasta el momento habían sido silenciados por los militares [...] eran hablados sin énfasis". ${ }^{46}$ En Tempo de resistência, como en el caso de la descripción de las torturas antes citadas, tampoco parecen ni mesurados ni sobrios el testimonio de Denise Crispim, con su llanto desconsolado ante la cámara, como ya vimos, ni el de Terezinha Zerbini cuando entre metáfora, cita y comparación traza una imagen bien viva del cuerpo torturado de Frei Tito: ${ }^{47}$

Estuve allá... en la... ocho días en la sucursal del infierno, porque aquella Operación Bandeirantes ${ }^{48}$ era la sucursal del infierno. Cuando oí un alboroto, " ¡entró vivo, tiene que salir vivo!", salté, a la silla, y vi a Tito saliendo con los brazos cortados, todo ensangrentado, parecía un cerdo cuando se lo desangra; pobre... ${ }^{49}$

\footnotetext{
${ }^{44}$ GAGNEBIN. Palavras para Hurbinek, p. 105.

${ }^{45}$ LEVI. Si esto es un hombre, p. 99.

${ }^{46}$ SARLO. Una alucinación dispersa en agonía, p. 2, cursiva de la autora.

${ }^{47}$ Sobre Frei Tito y su militancia se puede ver Batismo de sangue (Ratton, 2007), basado en la obra homónima de Frei Betto.

${ }^{48}$ OBAN: concentró acciones represivas contra grupos revolucionarios; creada en junio de 1969 para actuar en la región de San Pablo, era comandada por el Ejército.

49 "Fiquei lá... na... oito dias na sucursal do inferno, porque aquela Operação Bandeirantes era a sucursal do inferno. Quando eu ouvi um burburinho grande, 'entrou vivo, tem que sair vivo!', eu pulei, na cadeira, e olhei e o Tito ia saindo com os braços cortados, todo ensanguentado, parecia um porco quando você corta; coitadinho..." (TEMPO DE RESISTÊNCIA, 1:07:55 h, traducción y cursivas mías).
} 
¿Cómo interpretar estos “excesos"? En la misma introducción antes mencionada, Antelme también recuerda que los sobrevivientes tenían un "deseo frenético" de contar la experiencia que traían de los campos, que querían contarla con "pelos y señales". ${ }^{50}$ Esa necesidad imperiosa de decir, de describir y de explicar de los testigos, y la necesidad del repomalizador de incluir todo en el documental, puede ser pensada como búsqueda "frenética" de la palabra justa frente a la constatación de su insuficiencia, búsqueda de la expresión que realmente transmita la experiencia de lo vivido. Pero, ahí también se pueden leer las consecuencias de haberle negado a las víctimas un espacio de habla en el que pudiesen contar sus vivencias; según Teles los familiares de muertos y desaparecidos políticos y perseguidos por la dictadura, ante la Comisión Nacional de la Verdad, mostraron la angustia que genera no tener espacios políticos donde expresar su demanda y construir el relato de la experiencia vivida. ${ }^{51}$

\section{La escasez del relato}

¿Cómo conciliar la violencia ejercida por la guerrilla con la ética de la militancia? Ética esta que es diferente de la del torturador, agente del Estado que tiene a su disposición mecanismos legales para combatir a los que considera enemigos y que, sin embargo, viola todos los derechos y todos los tratados internacionales. Ética, la del militante, que incluiría generosidad, altruismo, sensibilidad, ${ }^{52}$ que estaría forjada con valores humanistas. ${ }^{53}$

\footnotetext{
${ }^{50}$ ANTELME. La especie humana, p. 6.

${ }^{51}$ TELES. $O$ abismo na história: ensaios sobre o Brasil em tempos de Comissão da Verdade, p. 44.

${ }^{52}$ El historiador brasileño y exdirigente de la Dissidência Comunista da Guanabara, Aaron Reis Filho traza un panorama de lo que es la ética revolucionaria para Engels, Mao Tsétung, Fidel Castro y Che Guevara (ver REIS FILHO. A revolução faltou ao encontro: os comunistas no Brasil, p. 121-122). También en documentos del PRT se puede leer sobre la ética del militante: "auténticas virtudes proletarias: humildad, sencillez, paciencia, espíritu de sacrificio, amplitud de criterios, decisión, tenacidad, deseos de aprender, generosidad, amor al prójimo" (PARRA. Moral y proletarización, p. 46-47; CARNOVALE. En la mira perretista: las ejecuciones del "largo brazo de la justicia popular", p. 33).

${ }_{53}$ TEMPO DE RESISTÊNCIA, 1:22:15 h, testimonio de Granville. Aunque Luis Mattini también alerta que eso no quita que hubiese "individuos con cierta patología..." (ERREPÉ, 00:31:06).
} 
Tal vez sea difícil la conciliación y difícil también el relato, lo que parece evidente en ambos documentales. De las varias acciones llevadas a cabo, Tempo de resistência se detiene en la descripción de las más espectaculares o heroicas como el asalto al tren pagador, ${ }^{54}$ el robo del cofre de Ademar de Barros, exgobernador de San Pablo, ${ }^{55}$ los secuestros de los embajadores de Estados Unidos ${ }^{56}$ y de Alemania ${ }^{57}$ y no profundiza en la muerte del primer policía ${ }^{58}$ y es sucinta sobre el ajusticiamiento del capitán Chandler, ${ }^{59}$ como veremos adelante. Errepé es bastante más abarcativo, pero como también se verá, los relatos, en general, se hacen a través del material de archivo.

A modo de ejemplo sobre la dificultad para referirse a la propia violencia veamos dos casos en Tempo de resistência. En el intertítulo "Después de la escisión del PCB, de la misma forma que en otros países, crece la opción por la lucha armada", ${ }^{60}$ la información principal es el comienzo de las acciones armadas, pero viene antecedida y "suavizada" por otras dos, una de las cuales (en cursiva) sirve para justificar y legitimar la opción. Se puede observar el mismo movimiento en algunas declaraciones, las más personales. Transcribo un ejemplo:

o [...] iba dócilmente a la cárcel o me exiliaba o luchaba... y para luchar tenía... tenía que... en realidad, que dar un paso adelante. Pero ese movimiento mío también coincide con el movimiento de la propia Dissidência, el de decidirse por la lucha armada, etc.... Yo fui una de las personas, tal vez... que más influenció dentro de la Dissidência para que se tomase ese rumbo. Soy responsable de eso, lo sé perfectamente... ${ }^{61}$

\footnotetext{
${ }^{54}$ TEMPO DE RESISTÊNCIA, 00:30:46 h.

${ }^{55}$ TEMPO DE RESISTÊNCIA, 00:49:38 h.

${ }^{56}$ TEMPO DE RESISTÊNCIA, 00:51:10 h.

${ }^{57}$ TEMPO DE RESISTÊNCIA, 1:17:15 h.

${ }^{58}$ TEMPO DE RESISTÊNCIA, 00:29 h.

${ }^{59}$ TEMPO DE RESISTÊNCIA, 00:35:30 h.
}

60 "Depois do 'racha' do PCB, da mesma forma que em outros países, cresce a opção pela luta armada" (TEMPO DE RESISTÊNCIA, 00:19:59 h, traducción y cursivas mías). 61 " [...] ou [...] ia docemente para cadeia, ou ia para o exílio, ou lutava... e para lutar eu tinha, eu tinha que... na verdade, que dar um passo à frente. Mas esse meu movimento também coincide com o movimento que a própria Dissidência fez, de decidir pela luta armada, etc... eu fui uma das pessoas, talvez e... que mais influenciou dentro 
A pesar de lo categórico de la afirmación final ("soy responsable..."), la cita tiene el mismo movimiento del intertítulo (pasajes en cursiva), de justificación y legitimación. También la metáfora (dar un paso adelante), la repetición y la demora en busca de la expresión justa exponen la dificultad de hacer palabras el recuerdo.

En Errepé la escasez de relatos personales puede leerse de otra forma. La narración de las acciones de "propaganda armada" 62 -aprovisionamiento de insumos médicos en un hospital, ${ }^{63}$ toma de una radio para difundir una proclama ${ }^{64}$ reparto de alimentos en el patio de una fábrica- $-{ }^{65} \mathrm{y}$ de algunos ajusticiamientos -caso Sallustro, ${ }^{66}$ Ranier- ${ }^{67}$ se hace mediante material de archivo. Esta forma permite, por un lado, que los y las protagonistas se explayen sobre los propios sentimientos: "la violencia nos producía temor", 68 "no te andabas cuidando el pellejo más allá de lo imprescindible", "sentía un cierto nerviosismo", ${ }^{70}$ "el Che Guevara decía: las primeras balas las enfrenté con el culo". ${ }^{71}$ Por otro, abre espacio para la reflexión sobre cómo se llegó a la violencia revolucionaria y las formas de ejercerla: "había un convencimiento de que eso era justo, de que era correcto", 72 "me parecía que era una forma de hacer política por otros medios [pero] que eso implicaba un gran riesgo [el de la militarización de la organización]", ${ }^{73}$ "tratábamos de que

\footnotetext{
da Dissidência para que se tomasse esse rumo. Sou responsável por isso, sei disso perfeitamente..." (TEMPO DE RESISTÊNCIA, 00:42:10 h, testimonio de Martina, traducción y cursivas mías).

${ }^{62}$ Acciones que servían para juntar provisiones para la lucha armada y estimular la movilización de masas (IAZZETTA. "De lo pequeño a lo grande": el PRT-ERP y las acciones armadas consideradas como cualitativamente menores (1971-1976), p. 12).

${ }^{63}$ ERREPÉ, 00:21:13 h.

${ }^{64}$ ERREPÉ, 00:25:40 h.

${ }^{65}$ ERREPÉ, 00:25:49 h.

${ }^{66}$ ERREPÉ, 00:29:16 h.

${ }^{67}$ ERREPÉ, $1.20 .51 \mathrm{~h}$.

${ }^{68}$ ERREPÉ, 00:22:10 h, testimonio de Carmarero.

${ }^{69}$ ERREPÉ, 00:23.56 h, testimonio de Draguicovich.

${ }^{70}$ ERREPÉ, 00:23:12 h, testimonio de Ponce de Léon.

${ }^{71}$ ERREPÉ, 00:24:47 h, testimonio de Paz.

${ }^{72}$ ERREPÉ, 00:23:40 h, testimonio de Malacalza.

${ }^{73}$ ERREPÉ, 00:26:31 h, testimonio de Gutiérrez.
} 
las acciones nuestras fueran lo menos sanguinarias posibles", ${ }^{74}$ "hemos organizado atentados contra ciertos torturadores donde se fue a matarlos en cualquier condición que se diera" ${ }^{75}$

Tal vez sea porque hay una vivencia hecha experiencia, ${ }^{76}$ que los realizadores optaron por presentar esas secuencias de las reflexiones acompañadas por el mismo tipo de encuadre que Tempo de resistência usa cuando se trata de tortura: entrevistadas y entrevistados fuera de cuadro y fragmentados; para indicar que por más solidarias y valientes que puedan sonar las reflexiones ahí hay una experiencia también traumática.

Quizás donde sea más difícil la conciliación entre ética y violencia revolucionaria es en el tema de los ajusticiamientos. Según Gorender, ${ }^{77}$ son actos de justicia revolucionaria; se ejecutan enemigos y compañeros acusados de traición. ${ }^{78}$ Para Brasil, el mismo autor consigna seis casos, de los cuales sólo uno está tratado en Tempo de resistência, el del capitán Chandler (12/10/1968), un militar estadounidense que vino a América del Sur a enseñar técnicas de tortura a brasileños y uruguayos después de haberlas practicado en Vietnam. ${ }^{79}$ En una secuencia sucinta, poco más de un minuto (00:35:30-00:36:34), se oye la información anterior seguida de una declaración explicativa:

\footnotetext{
${ }^{74}$ ERREPÉ, 00:27:28 h, testimonio de Camarero.

${ }^{75}$ ERREPÉ, 00:30:37 h, testimonio de Mattini.

${ }^{76}$ Aquí pienso en la diferencia entre vivencia y experiencia en el sentido hegeliano. Como dice De Marco para los campos de concentración nazi, la experiencia no supone solo la reflexión sobre lo vivido, incluye también la reflexión sobre el conocimiento construido (DE MARCO. A literatura de testemunho e a violência de Estado). De ese modo, si la vivencia de los campos de concentración les cupo a unos cuantos millones de personas, la experiencia de la aniquilación racionalmente administrada es una herencia que todos recibimos.

${ }^{77}$ GORENDER. Combate nas trevas, p. 273.

${ }^{78}$ Tanto Gorender (Combate nas trevas) como Mattini (Los perros: memorias de un combatiente revolucionario) coinciden en que en algún momento las militancias fueron tomadas por el miedo a la infiltración o la obsesión de la traición. En Errepé se hace referencia a infiltraciones en general y se muestra la tapa de una publicación con el caso Ranier. Tempo de resistência no aborda el tema.

${ }^{79}$ Ver TEMPO DE RESISTÊNCIA, 00:35:22 h.
} 
[...] con toda franqueza, me pareció muy justo [el ajusticiamiento], porque él como otros, vinieron aquí a hacer el trabajo sucio del gobierno norte americano y a enseñar tortura a nuestros... a nuestra represión, vinieron aquí para eso. Entonces, me parece absolutamente justo, en el momento que la lucha está radicalizada y ellos están matando compañeros en la tortura, que muriese ese tipo también, ¿por qué no ${ }^{80}$

A pesar de lo franco y contundente de la declaración, la explicación del motivo del ajusticiamiento y del sentimiento de justicia, en planos cortos que acentúan la dramaticidad, eso es todo lo que hay referido al hecho. La secuencia termina con un fundido a negro y un silencio posterior, que dejan resonando lo que se acaba de oír, como si no hubiese palabras para agregar.

Una observación más sobre la cita: en el "nuestros... nuestra represión", suponiendo que la palabra que acompañaría a "nuestros" fuese "represores", Granville se corrige como si no pudiese hacer suyos seres humanos tan perversos, capaces de tamaña violencia; pero al hacerlo, queda algo abstracto, sin rostro humano (que al final es lo que también son los torturadores). En Tempo de resistência esa abstracción se repite algunas veces cuando se hace sujeto a la "dictadura" y no a los militares y sus cómplices.

En Errepé las tres acciones de ajusticiamiento consignadas, el caso Oberdan Sallustro, director general de la fábrica Fiat en Argentina, ${ }^{81}$ el del capitán Humberto Viola y la muerte de una de sus hijas ${ }^{82}$ y el del infiltrado, Ranier, ${ }^{83}$ aunque con profundidad de tratamiento desigual, son tres momentos de lo que Portelli llama "memorias perturbadoras". ${ }^{84}$

80 “" [...] com toda franqueza, achei muito justo, porque ele, como outros, eles vieram aqui fazer o trabalho sujo do governo norte-americano e ensinar tortura aqui para nossos... para nossa repressão, eles vieram aqui para isso. Então, acho absolutamente justo, no momento em que a luta está radicalizada e que eles já estavam matando companheiros lá na tortura, que morresse esse cara também, por que é que não..." (TEMPO DE RESISTÊNCIA, 00:36.04, testimonio de Granville, traducción mía).

${ }^{81}$ ERREPÉ, 00:29:16 h.

${ }^{82}$ ERREPÉ, 1:12:00 h.

${ }^{83}$ ERREPÉ, 1:20:51 h.

${ }^{84}$ PORTELLI. Sobre los usos de la memoria: memoria-monumento, memoria involuntaria, memoria perturbadora. 
En principio, la primera acción y la última se justificarían dentro de la lógica de guerra de la guerrilla: tal vez por eso el documental se demora menos en esas acciones. En el caso Sallustro, observemos el siguiente diálogo entre entrevistado y entrevistador:

Mattini: no es lo mismo agarrar y a un tipo que está sentado ahí, por más enemigo que sea, pegarle un tiro, eso es... eso no es... no es resistible; eso no creo que lo pueda resistir una persona con... con... este... con ideales, yo no sé de un caso que se le pueda pegar un tiro a una persona que está sentada indefensa. ${ }^{85}$

Voz off: en algún momento [...] decías de la persona que está sentada y desarmada... pensaba en el caso Sallustro... [...] y... alguien lo mató... ${ }^{86}$

La intervención del entrevistador no solo muestra su compromiso con la verdad, como también acentúa la credibilidad del documental al no evadir las preguntas difíciles (y las respuestas también), formuladas desde un lugar solidario con la lucha revolucionaria ${ }^{87}$ Además, corrobora la afirmación hecha al comienzo de este artículo referida a que muchos de los documentales de memoria incluyen lo perturbador.

${ }^{85}$ ERREPÉ, 00:29.19 h. Continúa una secuencia con material de archivo sobre el secuestro de Sallustro (ERREPÉ, 29.35 h).

${ }^{86}$ ERREPÉ, 00:30:22 h.

${ }^{87}$ Aun cuando este trabajo no profundiza sobre el papel de los realizadores, aquí me gustaría abrir un paréntesis sobre otra diferencia, aunque externa a los documentales. Pensemos en la intervención que acabo de citar y las declaraciones de André Ristum ante el pedido de rectificación de Celso Lungaretti, acusado de traidor por Darcy Rodrigues, uno de los testigos en Tempo de resistência. El director afirma que su empresa fue contratada por Leopoldo Paulino para realizar la obra basada en su libro. "De esa manera, [...] el responsable del contenido es el propio Leopoldo Paulino. Yo, por mi corta edad, jamás podría responsabilizarme por informaciones sobre una época que no viví y que conozco poco" ("Assim, [...] o responsável pelo conteúdo [...] é o próprio Leopoldo Paulino. Eu, até pela minha pouca idade, não poderia jamais me responsabilizar por informações a respeito de uma época que não vivi e pouco conheço.”) (LUNGARETTI. Tempo de incoerência, cursivas mías). La comparación es importante ya que ratifica, junto con los otros aspectos que vengo abordando, la relación diferente que ambos países tienen con la memoria. Se puede leer sobre ese episodio y su rectificación en GORENDER. História. Folha de S. Paulo. 
En ese sentido, el documental argentino también se demora en el caso del Capitán Viola, "la tragedia de Tucumán", ${ }^{88}$ en la que el militar es ajusticiado y muere también una de sus hijas pequeñas, que iba con él en el coche que manejaba; la otra queda herida. De forma semejante al caso Sallustro, pero contado por otro militante, Juan Carlos Ledesma, la narración surge durante la reflexión sobre el trato dado a los prisioneros: "nosotros somos respetuosos de los tratados de Ginebra en relación al tratamiento de los prisioneros de guerra". ${ }^{89} \mathrm{El}$ ajusticiamiento se produjo como represalia por el asesinato de 15 compañeros, en el marco del Operativo Independencia, ${ }^{90}$ en Tucumán. La dirección del ERP asumió "la responsabilidad política de que uno de [sus] comandos [...] había cometido un gravísimo error violando la ética revolucionaria. En ese sentido la responsabilidad era política y moral..." ${ }^{91} \mathrm{Y}$ es así como la sienten los militantes en el documental; a modo de ejemplo transcribo solo uno:

[...] qué sé yo, una cosa digamos es... es matar a lo que se lleva a un... a un... [es matar] a un enemigo tuyo, viste... otra cosa, digamos, es meterte con la familia. Ese es el riesgo, digamos, que se corre, digamos, por una mala... yo, como te decía al principio, yo la táctica de la guerrilla, yo la veía como una táctica de autodefensa, viste, y de propaganda política, viste, y otra cosa, digamos, es el terrorismo, viste; o sea vos vas y metés el terror, digamos, en la población... si se quiere, viste, y... y yo creo que hubo algo de eso, viste... o sea se cayó, digamos, en un militarismo, en un terrorismo, viste, que desvirtuaba todo, viste, desvirtuaba todo porque... no tenés autoridad, cómo la justificás, no tenés justificación..$^{22}$

\footnotetext{
${ }^{88}$ MATTINI. Hombres y mujeres del PRT-ERP: de Tucumán a La Tablada, p. 260-262. ${ }^{89}$ ERREPÉ, 1:11:05 h, testimonio de Ledesma.

${ }^{90}$ Acción ordenada en 1975 por el gobierno constitucional peronista, comandada por el Ejército y la Fuerza Aérea argentinos, en la provincia de Tucumán, para aniquilar a la guerrilla.

${ }^{91}$ MATTINI. Hombres y mujeres del PRT-ERP: de Tucumán a La Tablada, p. 262.

${ }^{92}$ ERREPÉ, $1.13 .21 \mathrm{~h}$, testimonio de Gutiérrez.
} 
Ideas que demoran para salir, muletillas ${ }^{93}$ para ganar tiempo mientras se arma la idea, frases inconclusas que buscan un camino para decir lo injustificable. No hay sosiego para lo que pasó.

\section{A modo de conclusión}

Documental expositivo, abundante información, didactismo e intimismo; relatos de tortura y necesidad imperiosa de hablar en la película brasileña; documental participativo, confianza en el conocimiento de la historia y distanciamiento; reflexión sobre la violencia revolucionaria y sobre ajusticiamientos en la argentina. Se puede interpretar que estas diferencias formales están determinadas por los distintos caminos que recorrieron las representaciones del pasado en cada país.

Si dichas representaciones se articulan, entre otros factores, con diversos relatos - desde los de los organismos de DDHH hasta los de la literatura, el cine, la música, las artes plásticas; los estudios académicos, libros de textos y currículos escolares-, con conmemoraciones, musealizaciones y monumentalizaciones, con la actuación de la justicia y las políticas de Estado, ${ }^{94}$ en mayor o menor medida, todos esos elementos, menos los juicios (lo que no es poco), forman parte de la construcción de la memoria en ambos países. Asimismo, tanto en Brasil como en Argentina, se sostiene que en las memorias sobre ese período se borran apoyos, complicidades, colaboraciones y omisiones civiles. Entonces, ¿por qué las diferencias en los documentales? Creo que se puede encontrar una respuesta en los discursos construidos en la transición de las dictaduras a las democracias ya que serán estos los que se mantendrán durante años en las representaciones que sustentarán las memorias ${ }^{95}$ sobre los regímenes militares de cada país.

En Brasil, la memoria hegemónica de los años de lucha armada y de dictadura será construida, para mantener el consenso y la conciliación

93 "En general, [las] muletillas sirven para proporcionar al hablante el tiempo necesario para que vaya organizando mentalmente su elocución. Son, pues, formas dubitativas que amparan las vacilaciones expresivas de la lengua espontánea, peculiares de la improvisación [...]" (LOPE BLANCH, 1983 apud CHRISTL. Muletillas en el español hablado, p. 119).

${ }^{94}$ LVOVICH; BISQUERT. La cambiante memoria de la dictadura: discursos públicos, movimientos sociales y legitimidad democrática, p. 11.

${ }^{95}$ LVOVICH; BISQUERT. La cambiante memoria de la dictadura: discursos públicos, movimientos sociales y legitimidad democrática, p. 12. 
entre fuerzas antagonistas, atrás del escudo de la "resistencia"96 abrazado incluso por quienes participaron en las izquierdas armadas. La impunidad y el silencio predominarán desde la Ley de Amnistía, que si bien permitió que saliesen en libertad presos políticos y volviesen exiliados, no impulsó los juicios a los torturadores y a sus mandantes. Según muchos, es el precio que debió pagarse por la democracia. Así, en Brasil, en la construcción de la memoria, hay un desplazamiento: en lugar de poner el foco sobre los perpetradores de la violencia de Estado, se lo pone en la "resistencia". Podría decirse que ese desplazamiento forzó el olvido de las atrocidades cometidas por los agentes del Estado, que continúan impunes e influyentes. En Argentina, la memoria será un lugar siempre de enfrentamientos y al discurso de la guerra antisubversiva, con el cual los militares quisieron legitimarse, se le opondrá el del terrorismo de Estado, sostenido por las organizaciones de Derechos Humanos. En Argentina, tal vez se pueda decir, en 2019, que a pesar de las precariedades hubo un cambio de subjetividad, como lo muestran, por ejemplo, las grandes movilizaciones de 2017 contra la reducción de la pena a los condenados en los juicios de lesa humanidad. No vale lo mismo para Brasil. Aquí, sin que se haya juzgado a los torturadores (salvo a uno) y a sus mandantes, sin que se hayan encontrado los cuerpos de los desaparecidos, en 2018 gana la presidencia del país, democráticamente elegido, un hombre y un equipo que, entre otras barbaridades, celebran la tortura y la muerte, como se pudo ver durante el proceso de destitución de la presidenta Dilma Rousseff, cuando el actual presidente, que era senador en aquel momento, lo hizo homenajeando al coronel Brilhante Ustra, el primer militar reconocido por la justicia brasileña como torturador.

Diría que la diferencia de foco, sumada a la actitud inicial del estado argentino, que juzgó a los genocidas, el posterior reconocimiento de algunos militares -Scilingo (1995), Videla (2012)-de la participación del Estado en los crímenes cometidos, además de los juicios reabiertos desde 2003, fue construyendo una subjetividad diferente de la que se construyó en Brasil. Parecería claro que no puede tener el mismo efecto en la conciencia social -para conseguir verdad, justicia, repudio a la violencia de Estado- el recuerdo de las crueldades cometidas por el Estado que el recuerdo de un "tiempo de resistencia".

${ }^{96}$ ROLLEMBERG. Esquecimento das memórias, p. 5. 


\section{Referencias}

AGENCIA PARA LA LIBERTAD. Argentina. Testimonio de la sobreviviente Graciela Draguicevich ante la impunidad de sus torturadores genocidas. Kaosenlared, Terrassa, no paginado, may 9, 2017. Disponible en: https://kaosenlared.net/argentina-testimoniode-la-sobreviviente-graciela-draguicevich-ante-la-impunidad-de-sustorturadores-genocidas/. Acceso: 28 abr. 2019.

ANTELME, Robert. La especie humana. Traducción de Trinidad Richelet. Madrid: Arena Libros Editorial, 2001.

APREA, Gustavo. Documental, testimonios y memorias: miradas sobre el pasado militante. Ciudad Autónoma de Buenos Aires: Manantial, 2015.

BATISMO DE SANGUE. Director: Helvécio Ratton. Belo Horizonte: Quimera, 2006. Película,

CANDAU, Joël. Antropología de la memoria. Traducción de Paula Mahler. Buenos Aires: Nueva Visión, 2006.

CARNOVALE, Vera. En la mira perretista: las ejecuciones del "largo brazo de la justicia popular". Lucha Armada en la Argentina, Buenos Aires, n. 8, p. 4-22, dic. 2007.

CAZADORES DE UTOPÍAS. Dirección: David Blaustein. Ciudad Autónoma de Buenos Aires: Instituto Nacional de Cine y Artes Audiovisuales (INCAA), 1996. Película.

CHRISTL, Joachim. Muletillas en el español hablado. In: KOTSCHI, Thomas; OESTERREICHER, Wulf; ZIMMERMANN, Klaus (eds.). El español hablado y la cultura oral en España e Hispanoamérica. Madrid: Vervuert, 1996. p. 117-143.

CORTE PENAL INTERNACIONAL. Estatuto de Roma de la Corte Penal Internacional. Roma: [s.n.], 1998. Disponible en: https://www. un.org/spanish/law/icc/statute/spanish/rome_statute(s).pdf. Acceso: 25 jul. 2019.

DE MARCO, Valeria. A literatura de testemunho e a violência de Estado. Lua Nova, São Paulo, n. 62, p. 45-68, 2004. DOI: http:// dx.doi.org/10.1590/S0102-64452004000200004. Disponible en: http://www.scielo.br/scielo.php?script=sci_arttext\&pid=S010264452004000200004\&lng=en\&nrm=iso. Acceso: 7 sept. 2019. 
ERREPÉ. Dirección y producción: Gabriel Corbi y Gustavo de Jesús. Ciudad Autónoma de Buenos Aires: Nahuel Producciones, 2003. Película. Disponible en: https://www.youtube.com/watch? $\mathrm{v}=\mathrm{hnOBMATdj9k.}$ Acceso: 10 dic. 2014.

FOGLIA, Graciela. Confrontar lo indecible en el cine documental argentino y brasileño: los casos Urondo y Herzog. Caracol, São Paulo, v. 15, p. 308-340, maio 2018. DOI: https://doi.org/10.11606/issn.2317-9651. v0i15p308-341. Disponible en: https://www.revistas.usp.br/caracol/article/ view/134217. Acceso: 20 jun. 2018.

GAGNEBIN, Jeanne-Marie. Palavras para Hurbinek. In: NESTROVSKY, Arthur; SELIGMANN-SILVA, Márcio (org.). Catástrofe e representação. São Paulo: Escuta, 2000. p. 99-110.

GORENDER, Jacob. Combate nas trevas. São Paulo: Editora Fundação Perseu Abramo: Expressão Popular, 2014.

GORENDER, Jacob. História. Folha de S. Paulo, São Paulo, 30 set. 2004. Opinião. Painel do Leitor. Disponible en: http://www1.folha.uol.com.br/ fsp/opiniao/fz3012200411.htm. Acceso: 11 marzo 2018.

GUINZBURG, Jaime. Crítica em tempos de violência. São Paulo: EdUSP, Fapesp, 2012.

HÉRCULES 56. Dirección: Sílvio Da-Rin. [Rio de Janeiro]: A e A Produções Artísticas: Diálogo Comunicação, 2006.

IAZZETTA, Marco. "De lo pequeño a lo grande": el PRT-ERP y las acciones armadas consideradas como cualitativamente menores (19711976). Contenciosa, Santa Fe, n. 5, p. 1-23, II sem. 2015. Disponible en: http://www.contenciosa.org/Sitio/VerArticulo.aspx?i=50. Acceso: 30 jun. 2019.

LANZA, Pablo H. Usos del archivo en el cine documental latinoamericano contemporáneo: los documentos sobrevivientes. Cine Documental, Ciudad Autónoma de Buenos Aires, n. 1, no paginado, 2010. Disponible en: http://revista.cinedocumental.com.ar/1/articulos_03i.html. Acceso: 15 marzo 2015.

LEVI, Primo. Si esto es un hombre. Traducción de Pilar Gómez Bedate. 2. ed. Barcelona: Muchnik Editores, 2002. 
LUNGARETTI, Celso. Tempo de incoerência. Apesar de Você... 1964/1985, [S.l.], 21 jul. 2009. Disponible en: http://apesardevc19641985. blogspot.com/2009/07/tempo-de-incoerencia.html. Acceso: 5 dic. 2018.

LVOVICH, Daniel; BISQUERT, Jaquelina. La cambiante memoria de la dictadura: discursos públicos, movimientos sociales y legitimidad democrática. Buenos Aires: Los Polvorines; Universidad Nacional de General Sarmiento; Biblioteca Nacional, 2008.

MALDONADO, Aracely. La Vida aún está entera dentro mío. Comercio y Justicia, [Córdoba], 22 dic. 2010. Opinión, no paginado. Disponible en: https://comercioyjusticia.info/blog/opinion/la-vida-aun-esta-enteradentro-mio/. Acceso: 11 dic. 2019.

MANGONE, Carlos. "Por algo será". In: VINELLI, Natalia. ANCLA: una experiencia de comunicación clandestina orientada por Rodolfo Walsh. Buenos Aires: La Rosa Blindada, 2000. p. 9-10.

MATTINI, Luis. Hombres y mujeres del PRT-ERP: de Tucumán a La Tablada. La Plata: De la Campana, 2007.

MATTINI, Luis. Los perros: memorias de un combatiente revolucionario. Buenos Aires: Continente-Pax, 2006.

MONTONEROS, UNA HISTORIA. Dirección: Andrés Di Tella. [Buenos Aires]: Cine Ojo, 1998. Película.

NAPOLITANO, Marcos. Recordar é vencer: as dinâmicas e vicissitudes da construção da memória sobre o regime militar brasileiro. Antitesis, Londrina, v. 8, n. 15, p. 9-44, nov. 2015. DOI: http://dx.doi. org/10.5433/1984-3356.2015v8n15espp09. Disponible en: http:// www.uel.br/revistas/uel/index.php/antiteses/article/view/23617/17356. Acceso: 13 dic. 2018.

NESTROVSKI, Arthur; SELIGMANN-SILVA, Márcio. Apresentação. In: p. 7-12.

NICHOLS, Bill. La representación de la realidad: cuestiones y conceptos sobre el documental. Traducción de Josetxo Cerdán y Eduardo Iriarte. Barcelona: Paidós, 1997.

PARRA, Julio [Luis Ortolani]. Moral y proletarización. La Gaviota Blindada, [S.l.], n. 0, jul. 1972. 
PORTELLI, Alessandro. Sobre los usos de la memoria: memoriamonumento, memoria involuntaria, memoria perturbadora. Sociohistórica: Cuadernos del CISH, La Plata, n. 32, p. 108-117, 12 sept. 2013. Disponible en: http://www.memoria.fahce.unlp.edu.ar/art_revistas/ pr.6125/pr.6125.pdf. Acceso: 18 dic. 2017.

PRA FRENTE, BRASIL. Diretor: Roberto Farias. [Rio de Janeiro]: Embrafilme: Produções Cinematográficas R. F. Farias, 1983. Película.

REIS FILHO, Daniel A. A revolução faltou ao encontro: os comunistas no Brasil. São Paulo: Editora Brasiliense, 1989.

REPARE BEM. Diretora: Maria de Medeiros. Brasília: Comissão de Anistia e Reparação do Ministério da Justiça do Brasil; [São Paulo]: Instituto Via BR, 2013.

ROLLEMBERG, Denise. Esquecimento das memórias. In: MARTINS FILHO, João Roberto (org.). O golpe de 1964 e o regime militar. São Carlos: EdUFSCar, 2006. p. 81-91. Disponible en: https://es.scribd.com/ document/65543003/Aula17-ROLLEMBERG-Denise-O-esquecimentodas-memorias. Acceso: 15 sept. 2018.

SALVI, Valentina. De vencidos a víctimas: memorias militares sobre el pasado reciente en la Argentina. Buenos Aires: Biblos, 2012.

SARLO, Beatriz. Una alucinación dispersa en agonía. Punto de Vista, Buenos Aires, n. 21, p. 1-4, ago. 1984. Disponible en: http://www.ahira. com.ar/ejemplares/21-4/. Acceso: 30 jun. 2019.

TELES, Edson. O abismo na história: ensaios sobre o Brasil em tempos de Comissão da Verdade. São Paulo: Alameda, 2018.

TEMPO DE RESISTENCIA. Dirección: André Ristum. São Paulo: Sombumbo Filmes, 2004. Película. Disponible en: http://cinemaeditadura. com.br/tempo-de-resistencia/. Acceso: 20 enero 2015.

VLADO, 30 ANOS DEPOIS. Director: João Batista de Andrade. São Paulo: Oeste Filmes Brasileiros, 2005. Disponible en: https://www. youtube.com/watch?v=pB8XCSwyOeU. Acceso: 30 jun. 2019.

Recebido em: 15 de setembro de 2019, Aprovado em: 5 de dezembro de 2019. 